IP Periodica Polytechnica

Mechanical Engineering

57(1), pp. 21125 2013

DOI: 10.3311/PPme.7013

Creative Commons Attribution (1)

RESEARCH ARTICLE

\section{Relationship between the kink and the structure of the guidewire}

Péter Nagy, Liza Pelyhe

Received 2013-04-30

\begin{abstract}
The guidewire is a medical device which is used to wide range of vascular procedures. It is led to the target place to navigation the percutan coronary intervention devices. The fracture or breaking of the guidewire is about 0.1-0.8\% during this procedures. The guidewires' flexibility and kink resistance is different between the different guidewires and within the guidewire as well. It is influenced by the core material, the core diameter, and the tip style. In this study the core diameter, and the tip style was defined under stereo-, metallic microscope, and scanning electron microscope. The core material was same in the guidewire. The core diameter was significant lower in the distal end mem$\operatorname{ber}(31.7 \mu \mathrm{m} \pm 1.77 \mu \mathrm{m})$, than on the shaft portion $(176-343 \mu \mathrm{m})$ ( $p<0.001)$. The tip style was a Core-to-Tip. The helical coil made of a wire with about $76.35 \mu \mathrm{m}$ diameters, and with about $25.6 \mu \mathrm{m}$ gaps between the turns.
\end{abstract}

\section{Keywords}

guidewire $\cdot$ kink $\cdot$ structural investigation $\cdot$ structure $\cdot$ tip style

\section{Acknowledgement}

This work is connected to the scientific program of the "Development of quality-oriented and harmonized $R+D+I$ strategy and functional model at BME” project. This project is supported by the New Hungary Development Plan (Project ID: TÁMOP4.2.1/B-09/1/KMR-2010-0002).

\section{Péter Nagy}

BME, Faculty of Mechanical Engineering, Department of Materials Science and Engineering, H-1111 Budapest, Bertalan Lajos u. 7.

MTA-BME Research Group for Composite Science and Technology,, H1111 Budapest, Múegyetem rkp. 3, Hungary

e-mail: npeter@eik.bme.hu

\section{Liza Pelyhe}

BME, Faculty of Mechanical Engineering, Department of Materials Science and Engineering, H-1111 Budapest, Bertalan Lajos u. 7.

MTA-BME Research Group for Composite Science and Technology,, H1111 Budapest, Múegyetem rkp. 3, Hungary

e-mail: liza@eik.bme.hu

\section{Introduction}

Medical guidewire is used to wide range of coronary and peripheral vascular procedures, such as angioplasty, diagnostic, interventional, and percutaneous access procedures, or radiology and neuroradiology. The guidewire is entered to the body, and it reaches the target side through the various vascular branches following the tortuous vascular vessels by pushing and rotating the part of the guidewire which is outside of the patients. After the position of the guidewire medical devices may be delivered to the desired side by simply sliding over the guidewire [1, 3, 20, 21].

The length of the guidewire is between $50-300 \mathrm{~cm}$, and the outer diameter is $0.204-1.072 \mathrm{~mm}$. The guidewire has a shaft portion and a distal end which comprise a helical wound. The shaft portion consists of a core, on which may be a helical coil, furthermore a cover and/or coating which is on the core or on the helical coil (Fig. 11). The distal end has different structure, however the proximal end of the helical coil contain the flattened distal part of the core [2,4].

The guidewire has six parts, which can influence the performance characteristics and clinical relevance. It is the core material, the core diameter, the core taper, the tip style, the covers and coils, and the coating (Fig. 1] [4].

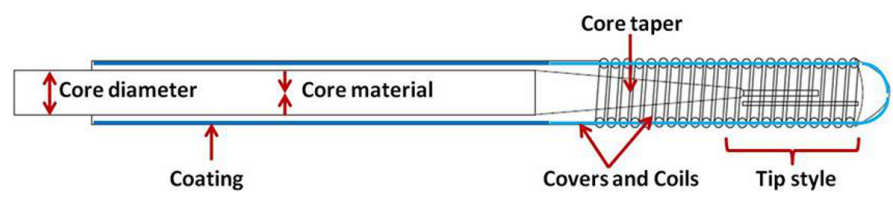

Fig. 1. The components of the guidewire

The core material usually made of type 304 stainless steel or Nitionol. The high tensile strength stainless steel has good flexibility, but Nitinol has excellent flexibility, and it is a superelastic alloy designed for kink resistance [4,5]. The smaller core diameter increases the flexibility, and enhanced the trackability. The larger diameter has more support and torque [4].

The taper influence the tracking and the support. Broad, gradual, or long tapers improve the tracking, but it has less support. Abrupt or short taper has greater support but greater tendency to prolapsed too [4, 5]. The tip style affects the steering and the 
softness. Two tip styles are distinguished: the Shaping-Ribbon (Fig. 2), and the Core-to-Tip style (Fig. 3). The Shaping Ribbon is softer and flexible, but the Core-to-Tip has precise steering and tip control [4,5].

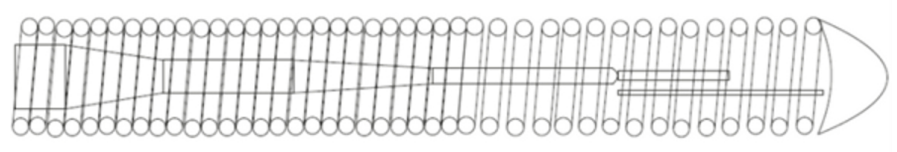

Fig. 2. Shaping-Ribbon tip

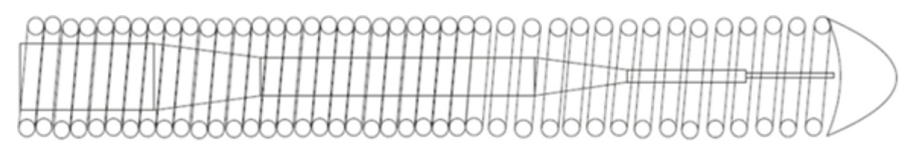

Fig. 3. Core-to-Top tip

The coils affect the support, the steering, the tracking, the visibility and the tactile feedback. The coil is located only on the tip or reached out outer the tip [4,5]. It made of material with $13 \mathrm{gramm} / \mathrm{cm}^{3}$ density, such as platinum alloy [6]. The cover is located on the distal end, and the distal end of the shaft portion. It made of polymer or plastic. It provide the lubricity [4, 5].The coating increase the trackability and minimized the friction. The coating may be hydrophilic or hydrophobic. It is located on the shaft. The hydrophilic coating is not use with cover [4,5].

The fracture or breaking of vascular procures which is terminated cardiac surgery, is about $2 \%$. The fracture or breaking of the guidewire is about $0.1-0.8 \%$ [7, 8]. The damage of the guidewire are caused by manufacturing fault $[9-12]$ or resulting from use [7, 13, 14]. The guidewires' flexibility and kink resistance is different between the different guidewires and within the guidewire as well. It is influenced by the core material, the core diameter, and the tip style [4-6] [15,-18].

In one documented case of one type of the guidewire was significant different the kink resistance between the distal end and the shaft portion of the guidewire [17]. In this article the explanation of this difference was aimed to find. We have shown that the core material, the core diameter, and the tip style influence the kink resistance [4,-6], [15,-18]. The core material was same along the guidewire therefore it was not cause the difference of kink resistance along the guidewire [19]. We have investigated the rest of the properties, the core diameter, and the tip style.

\section{Materials and methods}

The core material of the investigated guidewire made of 304 grade SS. The hidden structures were revealed by longitudinal section grinding. The cut distal end of guidewire was laid in resin (Spofadental Duracryl Plus). After its hardening the appropriate side was grinded and polished (Buehler Alpha).Micrometer (Mitutoyo was used to determine the diameter.The approximate size of the hidden structures was defined by reflected-light (metallic) microscope (Olympus PMG-3).The pictures were made by Nikon SMZ2T stereomicroscope with
Olympus Camedia 5500 digital camera, reflected-light microscope (Olympus PMG-3), and scanning electron microscope (Philips XL-30) equipped with energy-dispersive X-ray spectroscope (EDAX). The measure of the diameter was made three replicates. The main measured points were: the tip, the center of the distal end member, the joint of the distal end member and shaft portion. The other parts of the guidewire were also measured but randomly.

\section{Results}

\subsection{The core diameter}

\subsubsection{Guidewire diameter}

The guidewire diameter was marked on the packing $(360 \mu \mathrm{m})$. We have found that the diameter was changed along the guidewire (Fig. 4). Three transitions were found by between the joint of the distal end and shaft portion $(4 \mathrm{~cm})$, the phosphate coating transition $(7 \mathrm{~cm})$, and by $17 \mathrm{~cm}$ from the distal tip (Fig. 4).

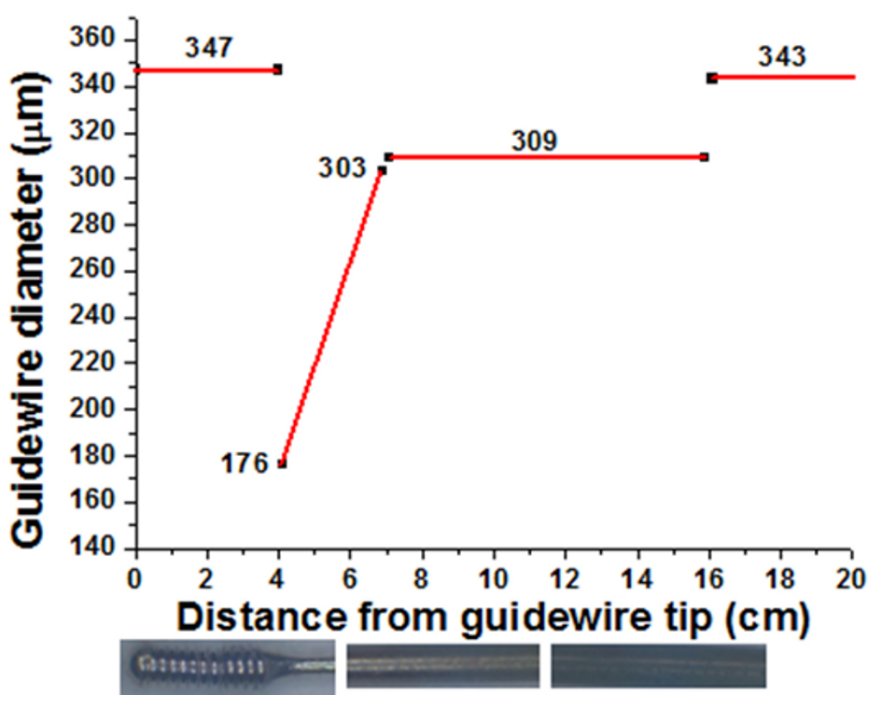

Fig. 4. The change of the guidewire diameter in function the distance from the guidewire tip

\subsubsection{Core diameter within the distal end}

The core diameter was not change within the distal tip (Fig. 5). Approximately the average size of the core diameter is $31.7 \mu \mathrm{m} 1.77 \mu \mathrm{m}$ (Fig. 5).

\subsubsection{Core diameter within the shaft portion}

The diameter of the shaft portion without phosphate coating was same as the diameter of the guidewire, i.e. increasing steadily from $176 \mu \mathrm{m}$ to $303 \mu \mathrm{m}$ (Fig. 4).

The thickness of the phosphate coating was only some $\mu \mathrm{m}$; it was removed, the core was shown (Fig. 6). The phosphate coating was damaged during the kink procedures. It was detached partially or completely from the core surface. The SEM-EDAX spectrum of the pop-up part under the damaged phosphate coating (Fig. 73) was compared with the SEM-EDAX spectrum of the coating (Fig. 7p) and the core (Fig. 7k) to prevent the origin 

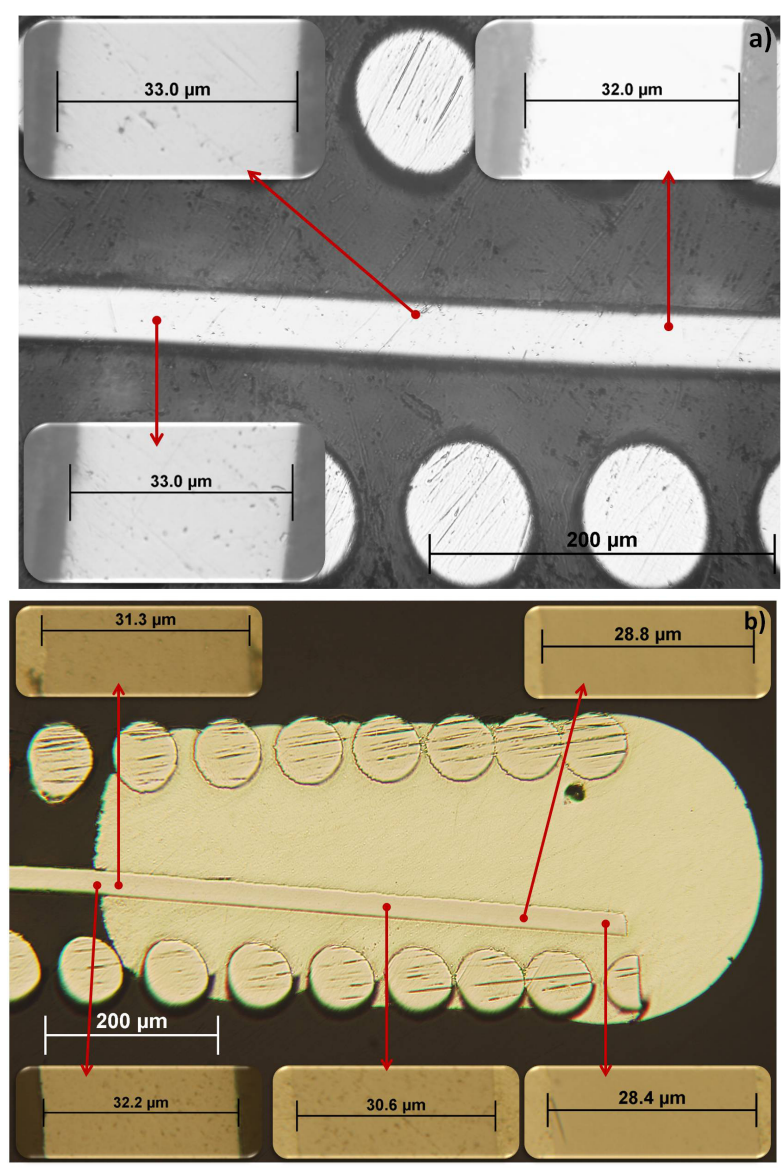

Fig. 5. The core diameter which are measured a) in the center of the helical coil, and b) in the solder, metallic microscopic photo

of the pop-up part. In the SEM-EDAX spectrum of the pop-up part there were the material of the coating and the core too. It is demonstrating that the core was laid under the coating.

\subsubsection{The change of the core diameter along the guidewire}

The average core diameter of the distal end was approximately $31.7 \mu \mathrm{m} \pm 1.77 \mu \mathrm{m}$. The core diameter of the shaft portion was increasing steadily from $176 \mu \mathrm{m}$ to $303 \mu \mathrm{m}$ from $4 \mathrm{~cm}$ to $7 \mathrm{~cm}$ measured from the distal tip, $309 \mu \mathrm{m}$ from $7 \mathrm{~cm}$ to $17 \mathrm{~cm}$ measured from the distal tip, and $343 \mu \mathrm{m}$ from $17 \mathrm{~cm}$ measured from the distal tip (Fig. 8). The core diameter was highly significant lower than the shaft portion diameter ( $\mathrm{p}$ 0.001, MannWhitney U test; two-tailed test).

\subsection{Tip style}

The tip style was defined by longitudinal section grinding (Fig. 9). The core was laid along in the distal end to the tip within the helical coil. This tip style called Core-to-Tip.

\subsection{Further structural investigations}

\subsubsection{The solder}

The length of the solder was approximately $771 \mu \mathrm{m}$, and it involved 7 spiral ring (Fig. 10a). The thickest diameter, which was the thickest part of the guidewire, was approximately $361 \mu \mathrm{m}$ (Fig. 10p). The rest part of the solder was within the helical coil; its diameter did not exceed the $347 \mu$ m diameter.
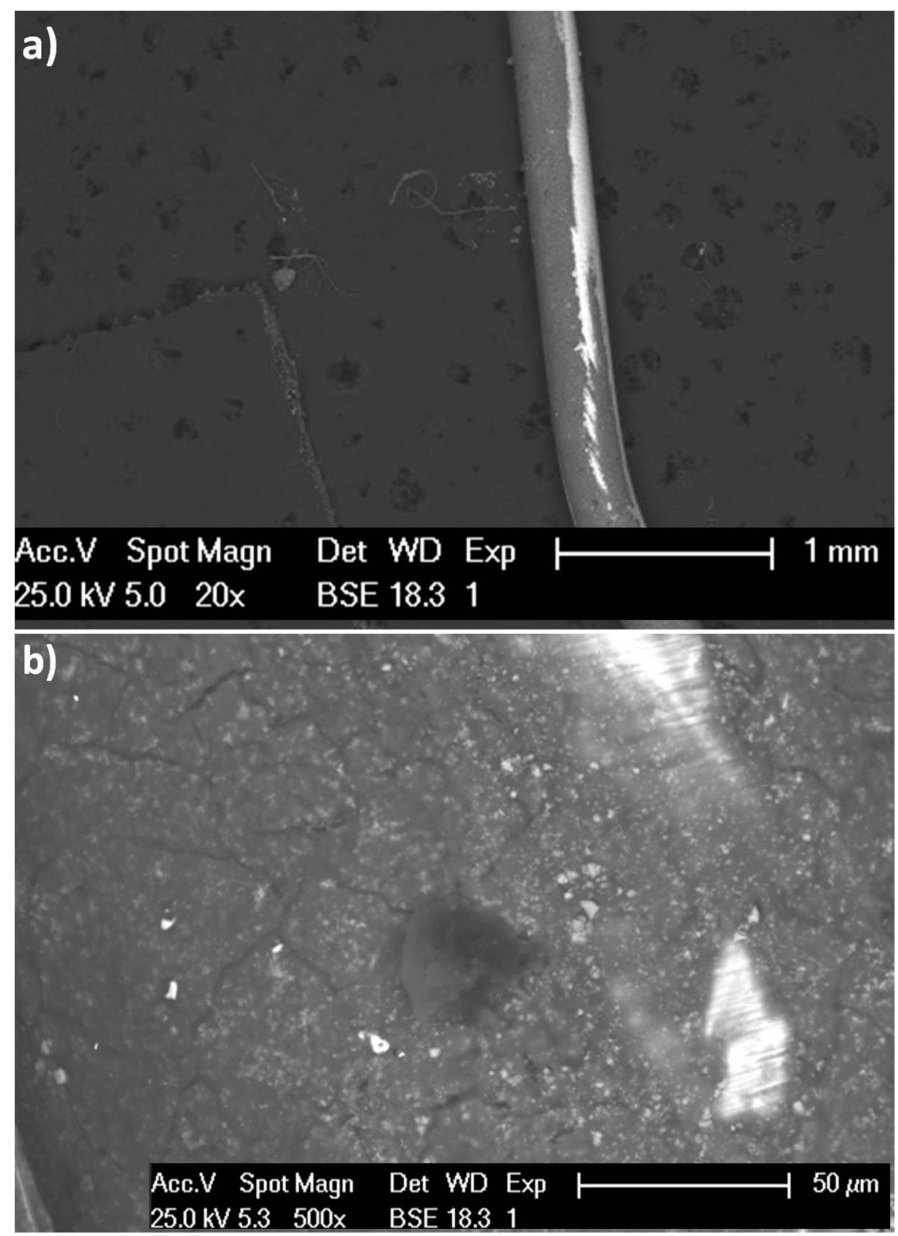

Fig. 6. The damaged phosphate coating a) small and b) higher magnification, SEM photo

\subsubsection{Helical coil}

Wire diameter: The average diameter of the wire of the helical coil was approximately $76.35 \mu \mathrm{m} 0.3 \mu \mathrm{m}$ (3-3 measure on the center of the helical coil and in the solder) (Fig. 11.

Gap between the turns: The average gap between the turns was approximately $25.6 \mu \mathrm{m} \quad 0.86 \mu \mathrm{m}$ (Fig. 12 ).

\section{Discussion and conclusions}

In this study we have investigated what influenced the different kink resistance between the distal end and the shaft portion of the guidewire. They were caused by the core material, the core diameter, and the tip style. The core material was same, therefore the other two parameters were defined. First of all the core diameter was investigated. The guidewire has three diameter transitions (between the joint of the distal end and shaft portion, by the phosphate coating transition, and by $17 \mathrm{~cm}$ from the distal tip), so the guidewire diameter was changed between 176-343 $\mu \mathrm{m}$. The core within the distal tip was made visible by longitudinal section grinding. The core diameter was $31.7 \mu \mathrm{m} 1.77 \mu \mathrm{m}$ here. This diameter is significant lower than the diameter of the shaft portion ( $\mathrm{p}$ 0.001, Mann-Whitney U test; two-tailed test).

The tip style was Core-to-Tip which contained the core whit about $31.7 \mu \mathrm{m}$ diameters and the helical coil, which made of 

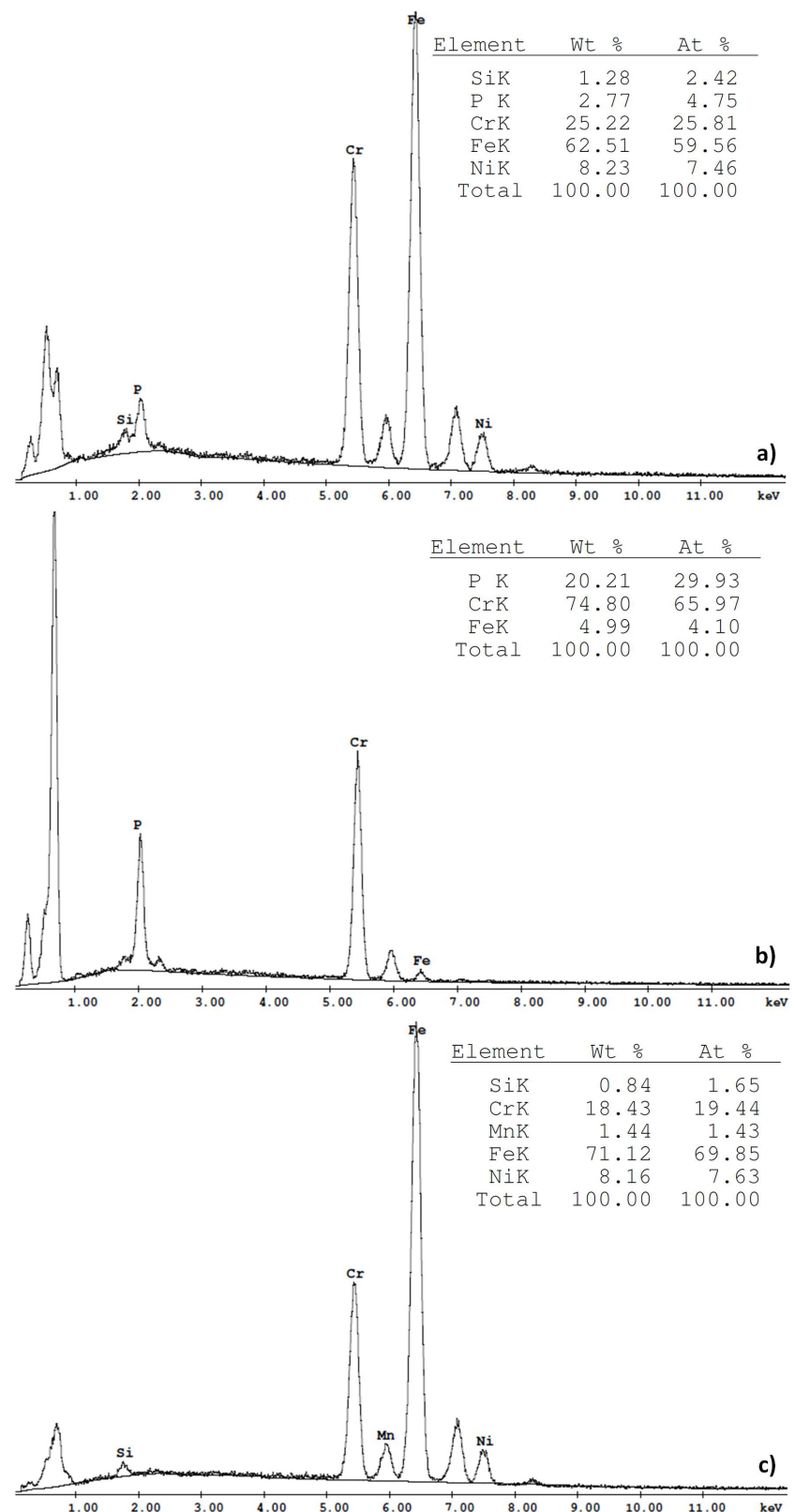

Fig. 7. The SEM-EDAX spectrum and the material composition of a) the part of the shaft portion under the phosphate coating $b$ ) the phosphate coating c) the core

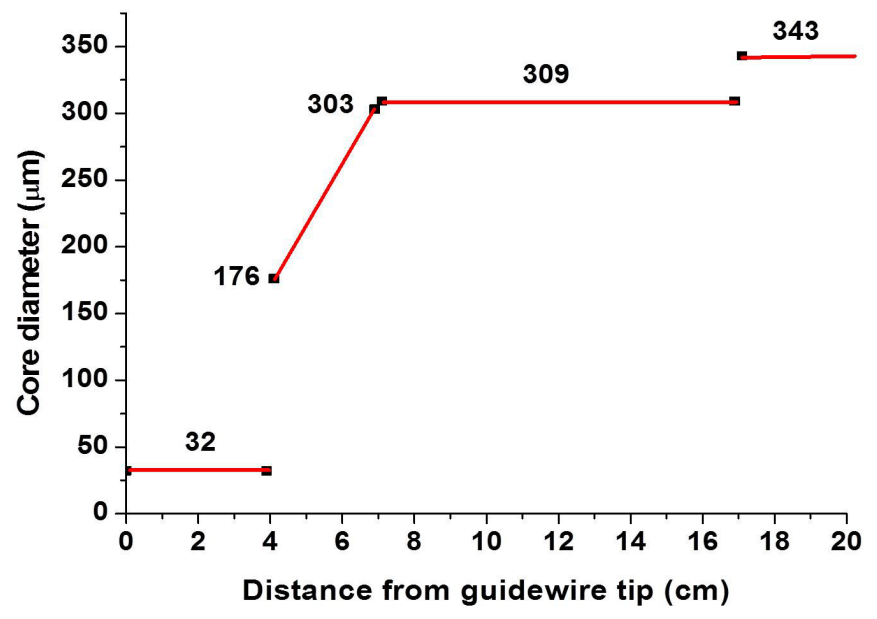

Fig. 8. The core diameter in function the distance from the distal tip

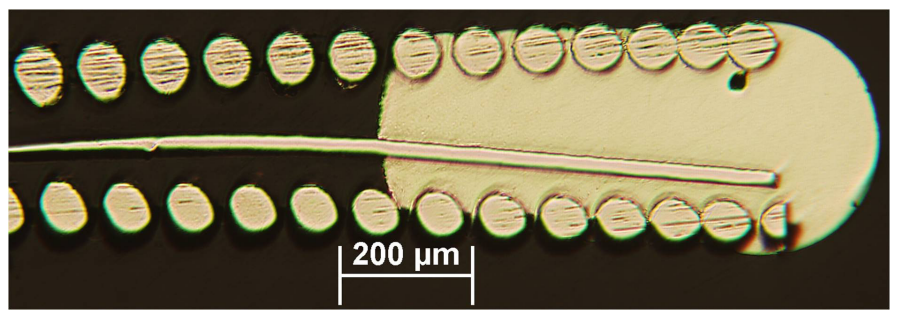

Fig. 9. The tip style of the investigated guidewire, metallic microscopic photo
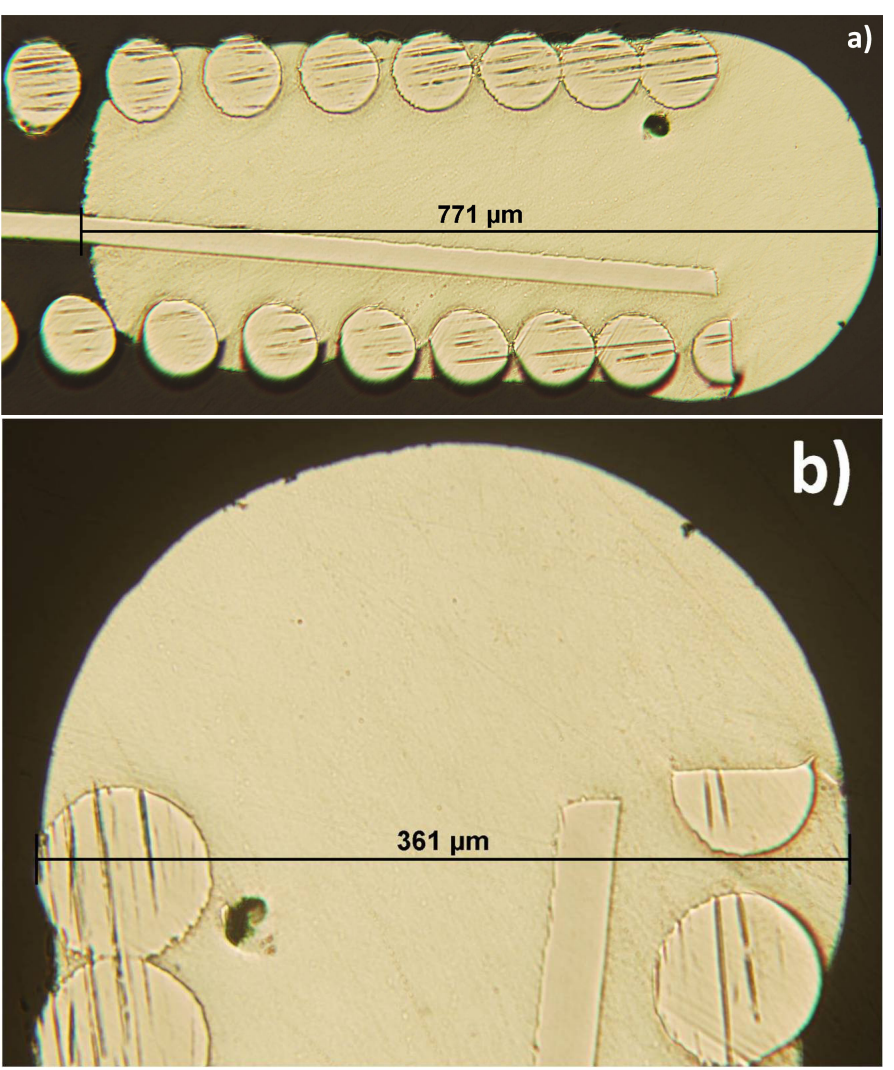

Fig. 10. Dimensions of the solder a) length b) diameter, metallic microscopic photo

wire with about $76.35 \mu \mathrm{m}$ diameters. The average gap between the turns was about $25.6 \mu \mathrm{m}$. We have shown that the structure of the different parts of the guidewire influenced the kink resistance.

The used methods and measures are suitable for investigation of another guidewires. They are useful widely, so soon we can compare the different types of the guidewires.

The flexibility and the kink resistance of the guidewire with Nitinol core material will be determined and compared to the guidewire with 304 grade SS core material. We suppose that the guidewire with Nitinol core material will be more flexible and it will have better kink resistance than the guidewire with 304 grade SS core material. They structure will be different from the guidewire with 304 grade SS core material. 

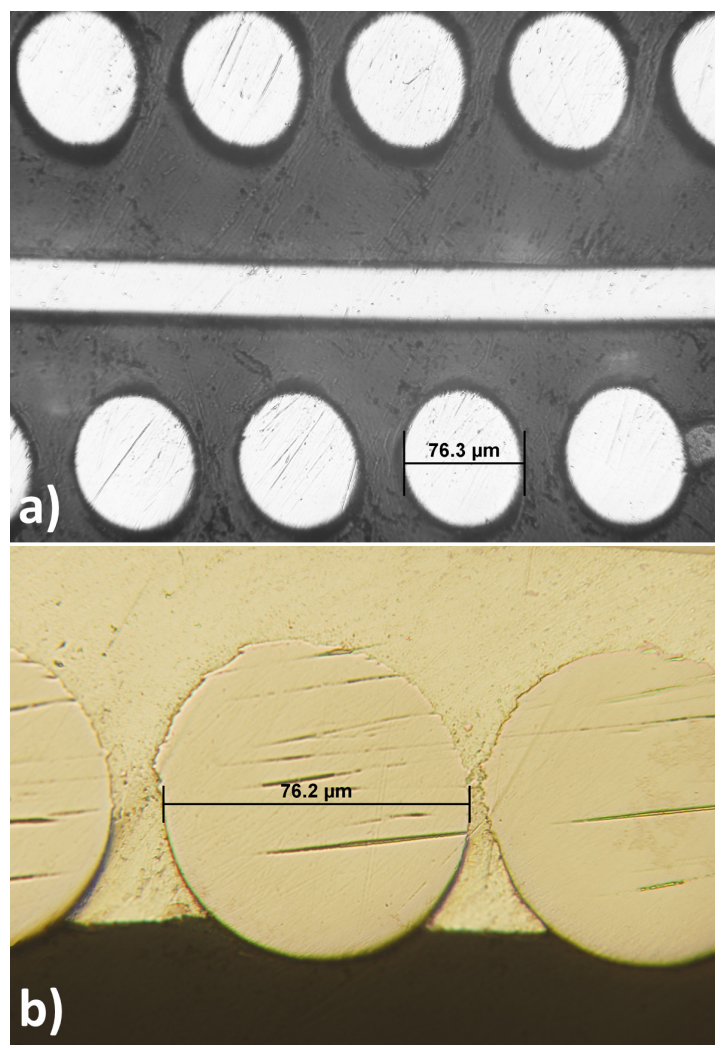

Fig. 11. One-one measure point of the wire diameter a) on the center of the helical coil and b) in the solder, metallic microscopic photo
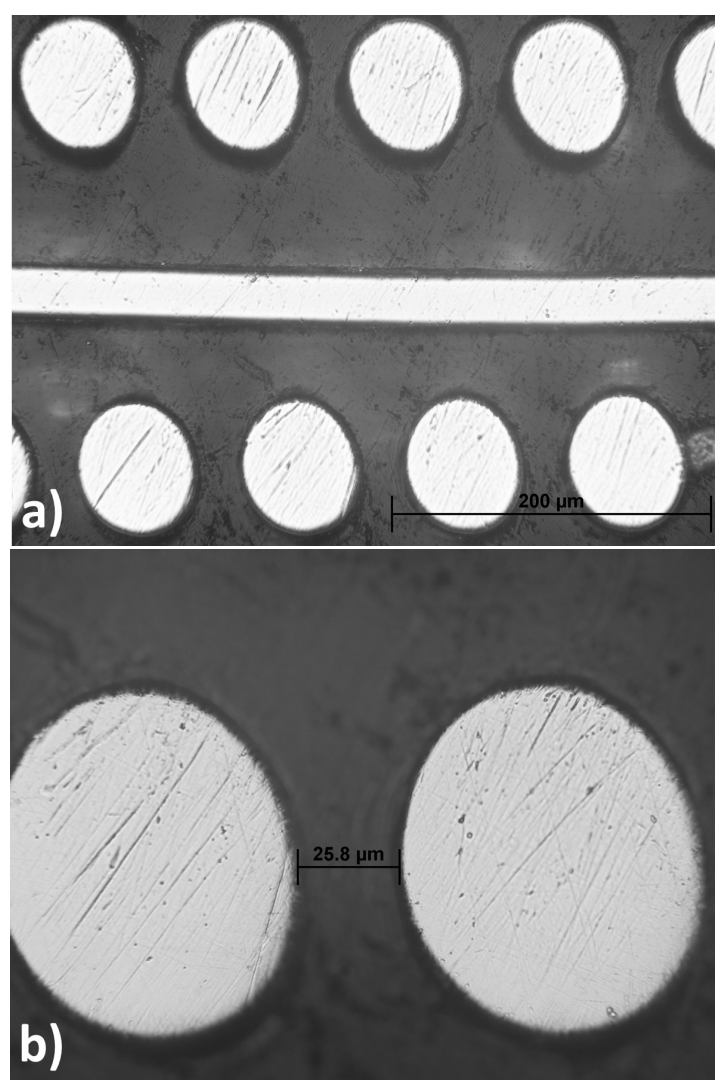

Fig. 12. a) The gap and b) its size, metallic microscopy photo

\section{References}

1 http://wWw. freepatentsonline.com/EP0714673A2/Access: 15.01 .2013

2 http://www . freepatentsonline.com/U6348041/Access: 15.01 .2013
3 Ohki T, Huang J, Comparing Interventional Guidewires in an Ex Vivo Model, Endovascular Today, 5, (2006), 26-29.

4 Craig T A, Anatomy of Contemporary CTO Guidewires and Selection Criteria-ppt presentation, Yale University School of Medicine, (2009).

5 Foust $\mathbf{R}$, Guide Wire Technology Engineering, http://wWw. leipzig-interventional-course.com/Access:26.03.2012

6 http://www.freepatentsonline.com /U4748986/ Access: 15.05.2012.

7 Balbi M, Bezante G, Brunelli C, Rollando D, Guide wire fracture during percutaneous transluminal coronary angioplasty: possible causes and management, Interact Cardiovasc Thorac Surg, 10(6), (2010), 992-994, DOI 10.1510/icvts.2009.227678

8 Demircan S, Yazici M, Durna K, Yasar E, Intracoronary guidewire emboli: a unique complication and retriveal of the wire, Cardiovascular Revascularization Medicine, 9(4), (2008), 278-280, DOI 10.1016/j.carrev.2007.11.003

9 James BA, McVeigh C, Rosenbloom S, Guyer E, Lieberman S, Ultrasonic Cleaning Induced Failures in Medical Devices, Journal of Failure Analysis and Prevention, 10(3), (2010-3), 223-227, DOI 10.1007/s11668010-9339-6

10 http://www.corrosionservices.com/newsletters/guidewire_ failure_analysis.html2012.05.10

11 http://www.fda.gov/Safety/Recalls/EnforcementReports/ ucm240447.htm2012.05.14

12 Monaca E, Trojan S, Lynch J, Doehn M, Wappler F, Broken guidewire - $a$ fault of design?, Canadian Journal of Anaesthesia, 52(8), (2005-8), 801-804, DOI 10.1007/BF03021773

13 Fischer R, Danger: beware of unretrieved device fragments, Nursing, 37, (2007:11), 17, DOI 10.1097/01.NURSE.0000298180.71588.13

14 Hong Y, Lee S, A case of guidewire fracture with remnant filaments in the left anterior descending coronary artery and aorta, Korean Circ J, 40, (2010-9), 475-477, DOI 10.40702Fkcj.2010.40.9.475

15 Schröder J, The mechanical properties of guidewires: Part II: Kinking resistance, Cardiovascular and Interventional Radiology, 16(1), (1993), 47-48, DOI $10.1007 / \mathrm{BF} 02603037$

16 Schröder J, The mechanical properties of guidewires: Part III: Sliding Friction, Cardiovascular and Interventional Radiology, 16(2), (1993), 93-97, DOI 10.1007/BF026002986

17 Pelyhe L, Bán $\mathbf{M}$, Bognár E, Kinking resistance of guidewires, Materials Science Forum, 729, (2013), 476-481, DOI 10.4028/www.scientific.net/MSF.729.476

18 Kocaturk 0, Active two-channel 0.035" guidewire for interventional cardiovascular MRI, Journal of Magnetic Resonance Imaging, 30(2), (2009), 461-465, DOI 10.1002/jmri.21844

19 http://www . abbottvascular.com/us/hi-torque-spartacore. html\{\#\} features2013.04.12

20 Bognár E, Ring G, Dobránszky J, Investigation of coated coronary stents, Materials Science Forum, 537-538, (2007), 307-314, DOI 10.4028/www.scientific.net/MSF.537-538.307

21 Bognár E, Ring G, Balázs T, Dobránszky J, Investigation of Drug Eluting Stents, Materials Science Forum, 589, (2008), 361-366, DOI 10.4028/www.scientific.net/MSF.589.361 